In assessing the need for these vaccines, we must first be sure that there is accurate information about the burden and cost of disease; we must know that the vaccines are safe, effective, easily administered and programmed, as well as cost-effective and acceptable to the community. It is also very important that there are satisfactory surveillance mechanisms in place to monitor disease incidences and vaccine-related adverse events.

As we enter an era where new vaccines are introduced that have been produced by sophisticated new biotechnologies, we will, at least in the short- to mediumterm, see these vaccines costing very much more than previously. There will be a need to assess the community's willingness to pay for this progress.

Of over-riding importance will be working to obtain a better understanding of the communication of risk, and of the behavioural and social changes affecting attitudes in our community-especially among parents of young children.

Historically, vaccines have prevented countless deaths and have brought long-term benefits that go far beyond health.

This article has been adapted from the Feery Oration, which was presented at the 8th National Public Health Association of Australia Immunisation Conference in Melbourne, during May 2002.

\section{REFERENCES}

1. Gandevia B. Tears often shed. Child health and welfare in Australia from 1788. Rushcutters Bay NSW: Pergamon Press (Australia); 1978.

2. Gidding HF, Burgess MA, Kempe A. A short history of vaccination in Australia. Med J Aust 2001;174:37-40.

3. Feery B. Impact of immunisation on disease patterns in Australia. Med J Aust 1981;2:172-6.

4. Gregg N McA. Congenital cataract following German measles in the mother. Trans Ophthalmol Soc Aust 1941;3:35-46.

5. Burgess MA. Gregg's rubella legacy 1941-1991. Med J Aust 1991;155:355-7.

6. McIntyre P, Gidding H, Gilmore R, et al. Vaccine preventable diseases and vaccination coverage in Australia, 1999-2000. Commun Dis Intell 2002;26 Suppl(May). Available at www.health.gov.au/pubhlth/cdi/pubs/pdf/vpd99_00.pdf.

7. Hull B, Lawrence G, MacIntyre CR, McIntyre P. Immunisation coverage: Australia 2001. Canberra: Commonwealth of Australia, 2002. Available at www.health.gov.au/pubhlth/immunise/report.pdf .

8. Leask J. Vaccination and risk communication: Summary of a workshop, Arlington Virginia, USA, 5-6 October 2000. J Paediatr Child Health 2002;38:124-8.

9. National Institute of Allergy and Infectious Diseases. The Jordan Report 20th Anniversary Edition. Accelerated Development of Vaccines 2002. US Department of Health and Human Services, National Institute of Health, 2002; www.niaid.nih.gov/dmid/vaccines/jordan20.

\title{
MAPPING IMMUNISATION COVERAGE AND CONSCIENTIOUS OBJECTORS TO IMMUNISATION IN NSW
}

\section{Brynley Hull and Peter McIntyre}

National Centre for Immunisation Research and Surveillance of Vaccine Preventable Diseases The University of Sydney and The Children's Hospital at Westmead

The Australian Childhood Immunisation Register (ACIR) commenced operation on 1 January 1996 and is now an important component of the Immunise Australia Program. Immunisations are generally notified to the ACIR either by electronic means - by email or the internet - or by hard copy notification forms. ${ }^{1}$ Parents with children who have a personal, philosophical, religious or medical belief that immunisation should not occur can ask their doctor or immunisation provider to complete a conscientious objection form and send it to the ACIR. In practice, this form is usually only completed if a parent wishes to receive means-tested child-care benefits and maternity allowances that are not paid unless a child is fully immunised or a conscientious objection form has been lodged.

From the immunisation data finally entered in the ACIR, the Health Insurance Commission (HIC) provides regular quarterly immunisation coverage reports at the national and state and territory level. Coverage for these reports is calculated using the cohort method. ${ }^{2}$ With this method, a cohort of children is defined by date of birth in threemonth groups. This birth cohort has the immunisation status of its members assessed at the three key milestones of 12 months, 24 months and six years of age. Definitions of coverage are based on the Australian Standard Vaccination Schedule and are described elsewhere. ${ }^{3,2}$

Calculation of immunisation coverage estimates by the $\mathrm{HIC}$ at the national and state level can hide pockets of low coverage within a state, and within a capital city. By calculating immunisation coverage for smaller geographical areas, it is possible to examine differences in immunisation coverage within states, and within capital cities, to identify specific areas of low coverage.

Poor uptake of immunisation is generally a result of a host of factors including: issues related to the medical history of a child; issues related to beliefs about the risks and benefits of vaccination; parental forgetfulness or poor access to immunisation services. ${ }^{4}$ The relative contribution of each of these factors to underimmunisation varies by population. One of the important 
and unique features of the ACIR is the facility to record a conscientious objection to immunisation. Low coverage in particular areas may be partly a result of a high proportion of conscientious objectors to immunisation residing in that area. By calculating the proportion of conscientious objectors in small areas, we can assess how much this proportion influences estimates of low vaccination coverage calculated on data from the ACIR.

Using ACIR data at September 2002, this article describes the mapping of immunisation coverage in NSW, including estimates and proportions of conscientious objectors to immunisation.

\section{METHODS}

Immunisation coverage estimates for 'fully immunised' at 12 and 24 months of age, and for measles, mumps and rubella (MMR) at 24 months of age were calculated from ACIR data. Two cohorts of children registered with Medicare, with a NSW postcode of residence on the ACIR, were analysed. The cohort born between 1 July 2000 and 30 June 2001 (a 12-month cohort) was used to calculate coverage at 12 months of age for Australian Bureau of Statistics (ABS)-defined Statistical Subdivisions (SSD) and Statistical Local Areas (SLA). ${ }^{5}$ The cohort of children born between 1 July 1999 and 30 June 2000 was used to calculate coverage at 24 months of age for the same geographical areas. We chose ABS-defined SSDs and SLAs as areas to be mapped because the mapping software we used, MapInfo, is restricted to these types of areas when creating maps. Coverage estimates were calculated for SSDs outside Sydney and for SLAs within Sydney. The number of children included in each cohort was approximately 86,000. As some 99 per cent of children born in Australia are registered with Medicare by one year of age, this source amounts to a census of all children born in NSW in these periods. Coverage was calculated using the cohort method described in Communicable Diseases Intelligence, March 1998. ${ }^{2}$

Rates of conscientious objection were calculated from the cohort of children registered with Medicare, with a NSW postcode of residence, born between 1 January 2001 and 31 December 2001. At the time of data extraction on 30 September 2002, the cohort was aged between nine and 20 months. We chose a different cohort when calculating the rates of conscientious objectors as we did not wish to include children under the age of nine months. The parents of these children would probably not have had enough time to object to immunisation as their children would have only received the first few of the due immunisations.

Maps were created using the MapInfo mapping software and the ABS Census Boundary Information. ${ }^{6}$ As postcode is the only geographical indicator on the ACIR, the ABS Postal Area to SLA Concordance 2001 was used to match ACIR postcodes to SSDs and SLAs, in order to create a SSD or SLA field for each child in the study cohort. ${ }^{7}$

\section{FIGURE 1}

NSW IMMUNISATION COVERAGE FOR ‘FULLY IMMUNISED’ CHILDREN AT 12 MONTHS, NSW, SEPTEMBER 2002

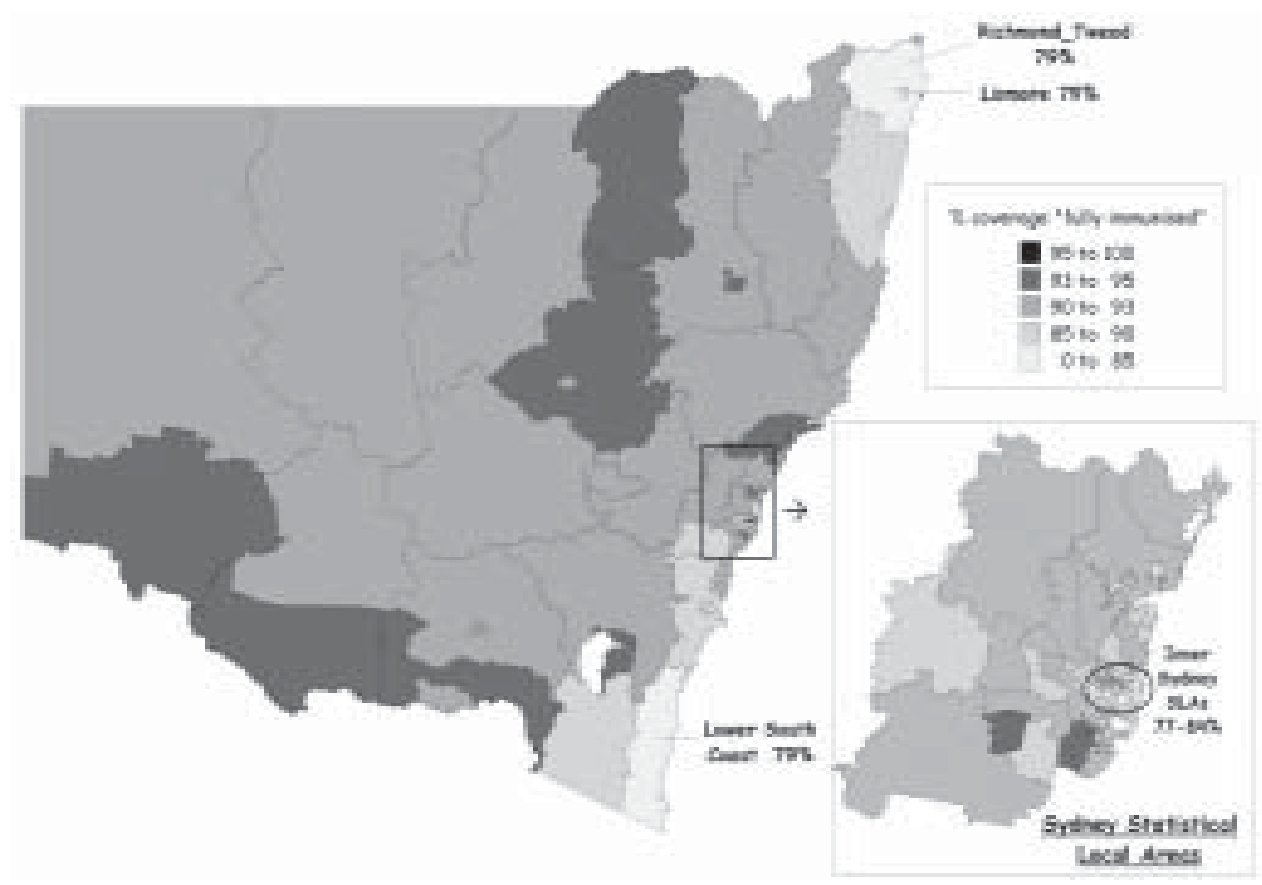

Source: Australian Childhood Immunisation Register 


\section{RESULTS}

The latest published figures from the ACIR show that immunisation coverage for children 'fully immunised' at 12 months of age for NSW was around 90 per cent. ${ }^{8}$ Figure 1 presents a map of immunisation coverage in NSW for 'fully immunised' at 12 months of age. Outside Sydney, the north coast SSDs of Lismore and Richmond-Tweed (including the Byron Bay SLA) and the lower south coast SSD (including the Bega Valley SLA) have the lowest coverage. Within Sydney, the lowest coverage was found in the inner-urban SLAs, from as low as 77 per cent in the Mosman SLA. Many other inner-urban SLAs have coverage less than 85 per cent-such as the Waverley, Woollahra, Sydney, South Sydney, Ashfield and Strathfield SLAs.

The latest published figures from the ACIR show that immunisation coverage for children 'fully immunised' at 24 months of age for NSW is around 88 per cent. ${ }^{8}$ The pattern of immunisation coverage at 24 months of age in NSW was quite similar to that for coverage at 12 months of age. Figure 2 presents coverage for 'fully immunised' at 24 months and those same SSDs of low coverage at 12 months were apparent at 24 months: the north coast SSDs of Richmond-Tweed (including the Byron Bay SLA), Lismore, and Clarence (including the Maclean SLA and the Coffs Harbour hinterland SLA), and the lower south coast SSD (including the Eurobodalla SLA). Low coverage in Sydney was again concentrated mainly in the inner-urban SLAs, with coverage ranging from 70-79 per cent, including Sydney, Mosman, Manly, North Sydney, Pittwater, Woollahra, Waverley, Randwick, Auburn and Strathfield.

Figure 3 shows immunisation coverage for MMR (measles, mumps and rubella vaccine) at 24 months of age in NSW. Overall, coverage was higher for MMR than it was for 'fully immunised' at 24 months, with many areas in NSW reaching greater than 95 per cent coverage. Areas of less than 90 per cent coverage included the Lismore and Richmond-Tweed SSDs in the north, the Blue Mountains SSD, the Pittwater SLA in Sydney, and many inner-urban SLAs of Sydney including Sydney, Mosman, Manly, North Sydney, Woollahra, Waverley, Randwick, South Sydney, Ashfield, Auburn and Strathfield.

Figure 4 presents a map of the proportion of notified conscientious objectors to immunisation in NSW. The average proportion of conscientious objection to immunisation in NSW was 0.4 per cent, with four areas of high proportions of objectors: the north coast SSDs of Lismore and Richmond-Tweed; the mid-north coast SSD of Port Macquarie; the Upper Murray and Snowy Mountains SSDs in southern NSW; and the Blue Mountains SLA west of Sydney. The greatest concentration of conscientious objectors in NSW was found in the Lismore and Richmond-Tweed SSDs, with rates of 4.2 per cent and 3.1 per cent, respectively, more than seven times the state average. Within the RichmondTweed SSD, the Byron Bay SLA had nine per cent of this cohort of children registered as conscientious objectors.

\section{FIGURE 2}

NSW IMMUNISATION COVERAGE FOR 'FULLY IMMUNISED’ CHILDREN AT 24 MONTHS, SEPTEMBER 2002

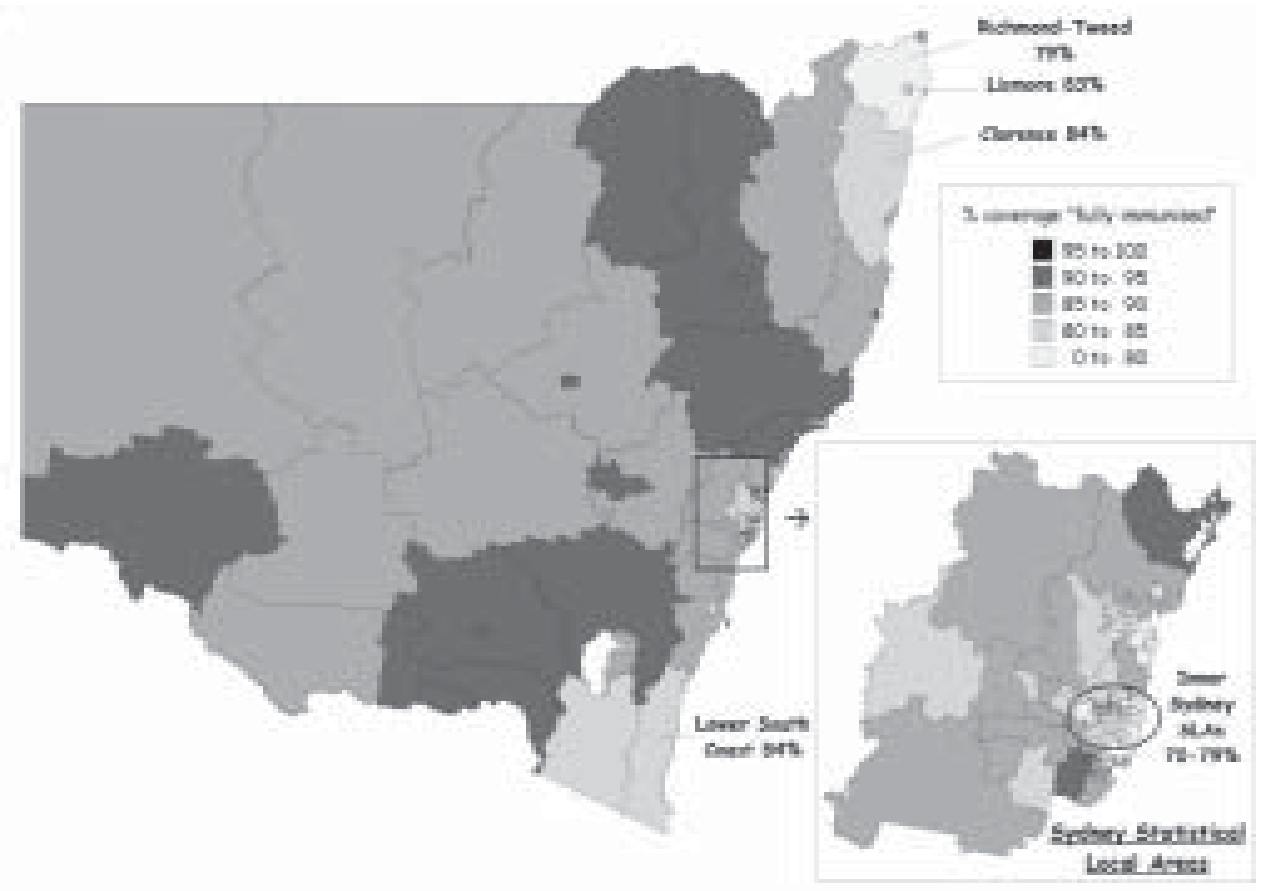

Source: Australian Childhood Immunisation Register 


\section{FIGURE 3}

NSW IMMUNISATION COVERAGE FOR MMR, CHILDREN AT 24 MONTHS, NSW, SEPTEMBER 2002

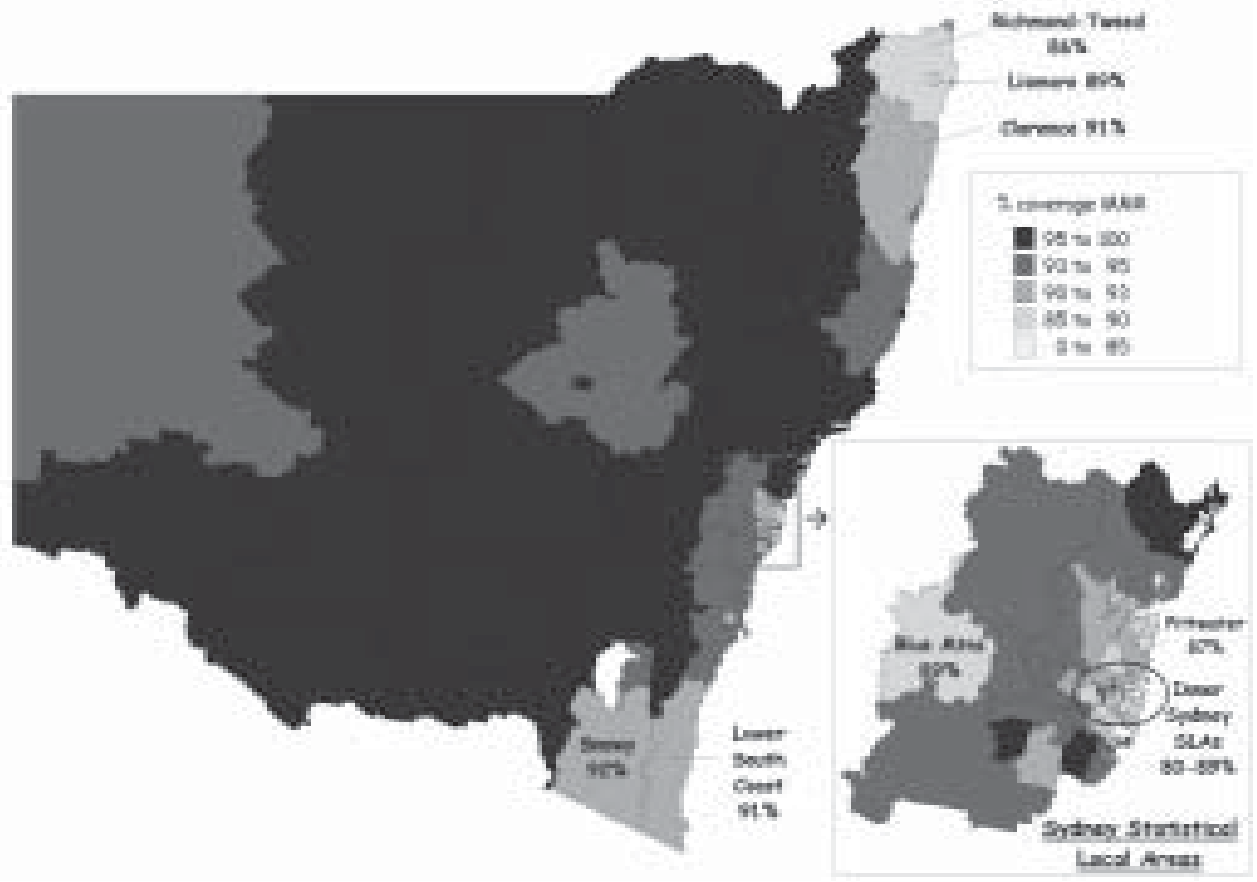

Source: Australian Childhood Immunisation Register

\section{FIGURE 4}

THE PROPORTION OF OFFICIAL CONSCIENTIOUS OBJECTORS TO IMMUNISATION, NSW, SEPTEMBER 2002

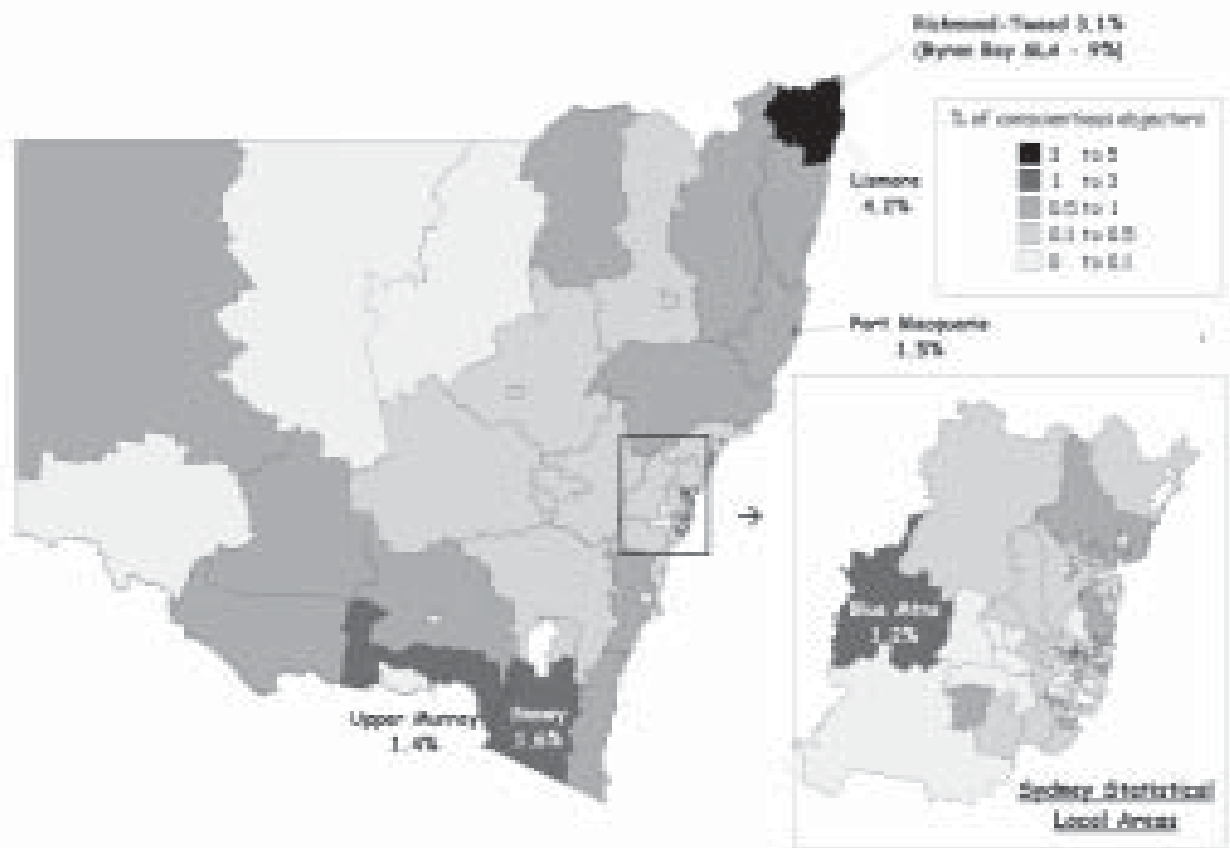

Source: Australian Childhood Immunisation Register 


\section{DISCUSSION}

Immunisation coverage in most of NSW is generally good with many areas achieving targets for coverage. Nevertheless, there are areas that have lower than optimal coverage across all vaccines and age groups, and the factors responsible for this may vary between urban and rural areas.

Coverage for the SSDs on the north coast was the lowest in the State, and these SSDs also had the highest level of registered conscientious objectors to immunisation. In contrast, those SLAs with low coverage in inner-urban Sydney do not exhibit the same high level of conscientious objection to immunisation, as recorded on the ACIR. There are two likely reasons for this difference. First, parents in inner-urban SLAs, such as Woollahra, Mosman, and Waverley, who object to immunisation are likely to have higher incomes than those in rural SLAs, and are therefore less likely to be eligible for means-tested child-care benefits and maternity allowances that are not paid unless a child is fully immunised or a conscientious objection form has been lodged. Therefore, many parents in innerurban SLAs may have no real incentive to officially object to immunisation by filling in a conscientious objector form. Non-immunising parents, who object to immunisation, residing in the north coast SSDs of NSW, and to a lesser extent in the south coast SSDs, are likely to have lower incomes and are more likely to be eligible for means-tested child-care benefits and allowances. Therefore, there is an incentive for these parents to register their objection to immunisation, because they will not receive benefits and allowances unless a conscientious objection form is lodged with the ACIR. Second, lower coverage in inner urban SLAs of the five largest Australian capital cities was recently shown to be related to less complete notification of immunisations by providers (primarily general practitioners), compared with either outer urban or non-urban SLAs practitioners. ${ }^{9}$

\section{CONCLUSION}

Although immunisation coverage has greatly improved over the past five years in NSW, and many areas have reached coverage targets, there are areas in NSW where the level of registered conscientious objection to immunisation is great enough to affect immunisation coverage, as measured by the ACIR. One such area is northern NSW, and the Byron Bay SLA in particular, where the rate of conscientious objection is one of the highest in the country. Additionally, the proportion of conscientious objectors on the ACIR is likely to be an underestimate of the proportion of parents who don't immunise because they disagree with immunisation, particularly in more economically advantaged areas. There are some non-immunising parents who 'object to registering', and they will refuse to complete any government-provided form. There are also those philosophically opposed non-immunising parents who have no real incentive to officially object to immunisation such as those in inner-urban SLAs. In some local areas, coverage may be sufficiently low for outbreaks of disease such as measles to occur among groups of objectors to immunisation, ${ }^{10,11}$ as recently observed in North Queensland. ${ }^{12}$

\section{REFERENCES}

1. Hull BP, McIntyre PB, Heath TC, Sayer GP. Measuring immunisation coverage in Australia. A review of the Australian Childhood Immunisation Register. Aust Fam Physician 1999;28:55-60.

2. O'Brien ED, Sam GA, Mead C. Methodology for measuring Australia's childhood immunisation coverage. Commun Dis Intell 1998;22:36-7.

3. National Health and Medical Research Council. The Australian Immunisation Handbook. 7th ed. Canberra: AGPS; 2000.

4. Commonwealth of Australia. Childhood Immunisation: A review of the literature. Canberra: AGPS; 1994.

5. Australian Bureau of Statistics. Australian Standard Geographical Classification. Canberra: ABS; 2001.

6. MapInfo. MapInfo Professional Version 7.0. MapInfo Corporation, 2002.

7. Australian Bureau of Statistics. Postal Area to Statistical Local Area Concordance. Canberra: ABS; 2001.

8. Commonwealth of Australia. Communicable Diseases Surveillance-Additional Reports. Commun Dis Intell 2002;26:491-3.

9. Hull, BP, Lawrence GL, MacIntyre CR, McIntyre PB. Immunisation Coverage: Australia 2001. Canberra: Commonwealth Department of Health and Ageing; 2002.

10. van den Hof S, Meffe CM, Conyn van Spaendonck MA, et al. Measles outbreak in a community with low vaccine coverage, the Netherlands. Emerg Infect Dis 2001;7(S-3): 593-7.

11. Feiken DR, Lezotte D, Hammen R, et al. Individual and community risks of measles and pertussis associated with personal exemptions to immunisation. J Am Med Assoc 2000;284:3145-50.

12. Hanna JN, Symons DJ, Lyon MJ. A measles outbreak in the Whitsundays, Queensland: the shape of things to come? Commun Dis Intell 2002;26:589-92. W 